\title{
Curare: from laboratory to law court
}

\author{
David R. Bevan, MB, MRCP, FRCA, FRCPC, CIM Editor-in-Chief (2003-2010) \\ Affiliation Department/Faculty, University of Toronto, Toronto, ON
}

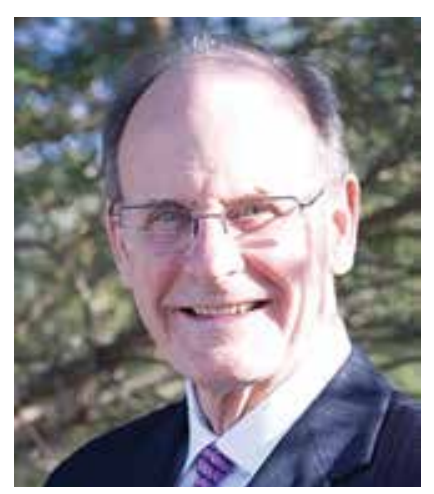

\begin{abstract}
$\mathrm{BIO}$
Dr. David Bevan held the Wesley-Bourne Chair of Anesthesia at McGill University, Chair of Anesthesia at UBC, Anesthetist-in-Chief at the University Health Network/Mount Sinai Hospital and subsequently Chair of the Department of Anesthesia at University of Toronto until his retirement in 2006. Dr. Bevan's research contributions included seminal work in neuromuscular blockade and this work, in addition to his expertise as a reviewer, led to several editorial appointments, including Editor-in-Chief for CIM (2003-2010). Dr. Bevan played a role in the introduction of the Anesthesia Care Team concept in Ontario. He published widely and was awarded multiple international professional honors.
\end{abstract}

"Only with the introduction of the routine use of muscle relaxants by Harold Griffith in Montréal in 1942 could it be said that the era of modern anesthesia had begun." NEJM 2000;34:42-9.1

The group of McGill anesthesiologists and University of Montreal pharmacologists was one of several around the world that were engulfed by the explosion of new knowledge, new drugs, new techniques of administration and measurement and new insights, that led to safer surgery and anesthesia. The aim of this article is to reflect on my 20 years of experiences in collaborations leading to the development of safe neuromuscular blocking drugs (NMBDs) in anesthesia and the importance of measurement in research.

The earliest report of the controlled use of muscle relaxation to facilitate general anesthesia was from Montreal by Harold Griffith and Enid Johnson in 1942'. The first patient, who was undergoing an appendectomy, was anesthetized with cyclopropane. Then, muscle relaxation was provided with small doses (3-5 cc) of a plant extract, Intocostrin ( $1 \mathrm{ml}=3 \mathrm{mg}$ curare) prepared by Squibb \& Co. The anesthesia record described "complete relaxation of the abdominal muscles resulted and continued for 20 minutes. There were no demonstrable changes in pulse, BP or respiration." With this development, anesthesia would be changed forever. No longer would it be necessary to achieve the triad of anesthesia, analgesia and muscle relaxation by using large, tox- ic doses of a general anesthetic agent. Separate drugs could be used for each component and operating conditions were dramatically improved. But not everyone was immediately enthusiastic. In 1954, Beecher and Todd analysed the outcome of 599,548 anesthetics in 10 Boston area hospitals and reported that the use of curare was associated with a six-fold increase in mortality ${ }^{2}$. Harold Griffith was a man of many achievements. He interrupted his medical studies at McGill University by serving as a stretcher bearer in World War I. He was awarded the Military Medal at Vimy Ridge for his “... cool and courageous behavior in dressing the wounded under heavy shell fire. One case being again wounded while he was dressing him..." ${ }^{3}$. Canada Post Corporation issued a stamp to honour Harold Griffith (1894-1985) in recognition of the introduction of curare into anesthesia.

I met Harold Griffith in Montreal in 1978. He had advanced Parkinson's Disease at the time. As he sat with his tremor and immobile facies, I asked "If curare gave so much trouble in Boston, why didn't you have any problems?" He turned to me slowly and, with a glimmer of a smile, replied "I reversed it with neostigmine".

\section{The search for the ideal muscle relaxant}

We live in an age that recognizes the importance of multidisciplinary approaches to provide better health care. For instance, in cancer care, nobody is surprised to see 
that the contributions of genetics, biochemistry, epidemiology, nuclear physics, radiotherapy, surgery and psychotherapy team together to improve patient outcomes. When experts combine their efforts, the results are inevitably better. The need to "strengthen collaborative research" is strongly recommended in the recent, seminal Naylor Report ${ }^{4}$.

Forty years ago, when my wife and I, both aspiring academic physicians, arrived in Montreal, nowhere was the lack of inter-disciplinary cooperation more evident than in our specialty of Anesthesia. Although Griffith and Johnson wrote that "the investigation should continue", Anesthesia Departments, at the time, resembled automobile garages more interested in tubes and fittings than research laboratories. The lack of dialogue between the pharmacologists and those who use their products was obvious when examining the literature. In the first half of the $20^{\text {th }}$ century, references to "curare" were sparse, limited to pharmacologists and physiologists and seldom if ever read by physicians. That was to change after curare came into more widespread use and, particularly, after the description of the first synthetic NMBD, pancuronium 5 . By the mid-1990s, the number of published curare articles had reached 4,000, and the Montreal group (Universities of Montreal and McGill) had contributed nearly $200^{6}$.

Inevitably, a large part of the surge in publications reflected pharmacological industry competition (two groups of drugs, aminosteroids and benzylisoquinolines, had been developed by competing manufacturers). The need to satisfy the chauvinism of national regulatory bodies encouraged new drug submissions to include studies performed within their jurisdictions. Consequently, the release of each new drug was associated with another publication blip; however, some of these studies did reveal important new scientific information that improved our understanding of the action of NMBDs. This information included the ability to recognize the correlation between clinical monitoring (trainof-four fade) and respiratory depression by Ali and Savarese in Boston; ; the development of sensitive assays to measure plasma concentrations of the NMBDs and their metabolites and to correlate them with neuromuscular effect $^{8-11}$. Bowman, in Glasgow ${ }^{12}$, improved our understanding of the neuromuscular junction with particular regard to NMBD effects and its measurement. Viby-Mogensen, in Copenhagen ${ }^{13}$, demonstrated the morbidity associated with residual neuromuscular block and its prevention. These and several other studies emphasized the contributions by many investigators around the globe. In Montreal, we were fortunate that our group had access to 1) both adults and children, which allowed age-related comparisons and 2) sensitive assays, which allowed pharmacodynamic-pharmacokinetic analyses ${ }^{14}$. We were particularly interested in the patterns of block produced in different muscles ${ }^{15,16}$, from the diaphragm to the thumb, and in the impaired recovery from neuromuscular blockade ${ }^{17}$.

\section{"Murder by Curare" in St. Etienne, France}

Early in 2009, I received an unusual letter from an ex-clinical fellow from Montreal, Luc Quentin. Would I act as an expert witness in a murder trial involving muscle relaxants? Although I agreed to participate, I was surprised because there are very few reports of curare being used as a murder weapon.

The case occurred in 1999 in St. Etienne, near Lyon, France ${ }^{18}$. A cleaning maid arrived to find André and Geneviève Gournier lying dead and fully dressed on a sofa and arm-chair, respectively. The couple had no obvious injuries and looked peaceful. In the apartment, the television was turned on, as was the gas stove, but the gas tank was empty. The bodies were taken to the undertakers and blood samples drawn for routine tests. It was assumed that they had both committed suicide, probably from carbon monoxide poisoning.

Their marriage had been stormy. André was a philandering husband and Geneviève was a retired nurse and had a colorful history in the French Resistance during World War II. Geneviève had often been heard to say to André, "I am going to kill you one day". Preparations were made for their funeral and burial. Although routine toxicology screening showed no evidence of sedatives or other drugs, it revealed the presence laudanosine, the metabolite of the NMBD, atracurium, in the plasma, urine and stomach of both subjects. The concentrations of laudanosine were compatible with the usual clinical paralyzing dose of atracurium during anesthesia. The Gourniers had died from atracurium-induced paralysis. 
It took several years of court encounters but, in 2008, the Gourniers' son, Jean-Paul Gournier (J-PG), a vascular surgeon, was convicted of their murder. There was a considerable amount of conflicting circumstantial evidence but the crucial evidence against J-P G was provided by anesthesiologists from Paris. They agreed that muscle weakness, after atracurium, occurred "within 30 seconds and that it was very unlikely that Mme Gournier would be able to move under such conditions". Thus, she would be unable to dispose of any paraphernalia if she had administered the drug and suicide, with subsequent disposal of any materials used by the victims, would have been impossible. J-PG was convicted of their murder and sentenced to 25 years of "reclusion criminelle". He had been in prison for one year when I was summoned as an expert witness to attend the review of the case in the Cour d'appel de Lyon, in June, 2009.

My appearance, on the last day of the review, was brief. My description of the pharmacology and pharmacokinetics of atracurium reflected a decade of careful research and clinical observations:

1. Concentrations of laudanosine found in the Gourniers were compatible with clinical doses of atracurium.

2. Onset of action of atracurium depends on the site. Paralysis of the arms and legs is relatively slow and is dose-dependent. The usual dose of atracurium given during anesthesia has maximal effect at about 2-3 min and, more slowly in the elderly.

3. It would be very easy to walk 2-3 metres (to the sofa and arm-chair) after administration of the atracurium.

Thus, it would have been possible for Mme Gournier to administer the atracurium to her husband and herself, dispose of the drug paraphernalia, and walk the short distance to the arm-chair. The result of the appeal came later that evening. We were enjoying dinner with Luc, when his cell phone rang. In European fashion, Luc left the table but we could see him getting agitated. He poked his head around the door: "Il est acquité. II est acquité." JP-G has now returned to his surgical practice. A murder mystery solved with knowledge of pharmacology and pharmacokinetics!

\section{Post script}

The last 20 years of the $20^{\text {th }}$ century could be regarded as the "golden years of muscle relaxants". Hundreds of investigators including physicians, basic scientists and pharmaceutical companies, from dozens of countries produced an explosion of new knowledge. What remains?

First, we have new and better drugs leading to safer anesthesia and surgery. It is unlikely that any new NMBDs will be developed. Cost-benefit calculations show that acquisitions are more profitable than new drug discovery.

Second, the co-operation of scientists and clinicians has continued to prosper, leading to a more mature view of clinical science with benefits to all. The spirit of progress has shifted in other directions but the co-operation survives.

Third, who would have thought that knowledge generated from studies that began in a small hospital in Montreal would have resulted, 70 years later, in the court rooms of Lyon, France, to allow a convicted murderer to be exonerated, released from prison and to continue his practice of vascular surgery?

"...the pursuit of truth, for its own sake, has overwhelmingly had the effect of exploding stereotypes, undercutting prejudice, and highlighting the connections between people..." David Reich, $2018^{19}$.

\section{REFERENCES}

1. Griffith HR, Johnson E. The use of curare

in general anesthesia. Anesthesiology.

1942;3:418-20

2. Beecher HK, Todd DP. Study of deaths associated with anesthesia and surgery.

Ann Surg. 1954;104:2-35

3. Military Medal Citation. 1917. A.F.W.3121.14-4-17.

4. Investing in Canada's Future. Strengthening the Foundations of Canadian Research. Canada's Fundamental Science Review. 2017

5. Buckett WR, Hewitt CL, Davage DS. Pancuronium bromide and other steroidal neuromuscular blocking agents containing acetylcholine fragments. J Med Chem. 1973;16:1116-24.

6. Carl J, Schwarzer M, Klingelhoefer D, Ohlendorf D, Groneberg DA. Curare - A Curative Poison: A Scientometric Analysis. PLOS ONE. 2014: 9(11): e112026. doi: 10.1371/journal.pone.0112026. 
7. Ali H, Wilson RS, Savarese JJ et al. The effect of tubocurarine on indirectly elicited train-of-four muscle response and respiratory measurements in humans. Br J Anaesth. 1975;570-4.

8. Hull CJ, Van Beem HBH, McLeod K et al. A pharmacokinetic model for pancuronium. Br J Anaesth. 1978;50:1113-22.

9. Hunter JM, Jones RS, Utting JE. Comparison of vecuronium, atracurium and tubocurarine in normal patients and in patients with no renal function. Br J Anaesth. 984;56:941-51.

10. Somogyi AA, Shanks CA, Triggs. Disposition kinetics of pancuronium bromide in patients with total biliary obstruction. Br J Anaesth. 1977;49:1103-08.

11. Stanski DR, Ham J, Miller RD, Sheiner LB. Pharmacokinetics and pharmacodynamics of d-tubocurarine during nitrous oxidenarcotic and halothane anesthesia in man. Anesthesiology. 1979;51:235-341.

12. Bowman WC. The neuromuscular junction: Recent developments. Eur J Anaesthesiol. 1985;2:59-93.

13. Viby-Mogensen J, Chraemmer Jorgensen B, Ording H. Residual curarization in the recovery room. Anesthesiology. 1979;50:53941.

14. Donati F, Varin F, Ducharme J, Gill SS, Theoret Y, Bevan DR. Pharmacokinetics and pharmacodynamics of atracurium, obtained with arterial and venous samples. Clin Pharmacol Ther. 1991;49:515-22

15. Donati F, Bevan DR Neuromuscular Blocking Agents. Fig 1614, p.443Chap 16 in Barash P. Clinical Anesthesia. pp 421-453, 2006

16. Donati F, Bevan DR Neuromuscular Blocking Agents. Table 162, p.427Chap 16 in Barash P. Clinical Anesthesia pp 421-453, 2006

17. Bevan DR, Donati F, Kopman AF. Reversal of neuromuscular blockade. Anesthesiology 1992;77:785

18. L'innocence empoisonnée. Jean-Paul Gournier, Caroline Dubanchet. Lulu.com 2012.

19. David Reich, Who We Are and How We Got Here. (Pantheon Books, New York, 2018).

CORRESPONDENCE TO:

E-mail david.bevan@utoronto.ca 